ISMC 2021

$16^{\text {th }}$ International Strategic Management Conference

\title{
APPLICABILITY OF BLOCKCHAIN TECHNOLOGY IN THE GLOBAL LOGISTICS SYSTEMS
}

\author{
A. Zafer Acar (a)*, Ovuakporoye E. Clarke (b) \\ *Corresponding author \\ (a)Piri Reis University, Tuzla, Istanbul, Turkey, azacar@pirireis.edu.tr \\ (b) Piri Reis University, Tuzla, Istanbul, Turkey, emmanuelclarke1@pru.edu.tr
}

\begin{abstract}
The 21st century has brought about Blockchain technology, which became a vital innovation in supply chain management and logistics. Blockchain technology is a digital ledger of replicated and disseminated transactions across all the nodes on the Blockchain network. Global logistics is the flow of data and resources between the point of origin and consumption. The arrival of the fourth industrial revolution enhanced the incorporation of technology into all logistics processes and led to the advent of Smart Logistics. The application of Blockchain technology in global logistics effectively advances and allows decentralization and immutable data storage. Blockchain technology has the capability to diminish errors, damage to goods, order delays, and multiple data entries. Essentially, Blockchain technology streamlines global logistics by making it more integrated, efficient, and transparent. The approach of this study can be described as a theory-building from multiple case studies. The study furnishes insight into Blockchain technology, its application and importance in global logistics and smart logistics, and possible opportunities and challenges to be encountered. The goal of this study is to emphasize how Blockchain technology can be advantageous to global logistics systems.
\end{abstract}

2357-1330 @ 2021 Published by European Publisher.

Keywords: Blockchain, global logistics, supply chain management, smart logistics 


\section{Introduction}

Blockchain technology is a developing and innovative technology that came into inception in recent years; its foundation is deeply rooted in cryptography, a branch of mathematics. Pilkington (2016) defined Blockchain as a distributed digital ledger employing encryption algorithms to prevent tampering. Blockchain is a reasonably new technology, can achieve anonymity, decentralization, transparency, realtime peer-to-peer operation, integrity, and irreversibility in a widely applicable manner encompassed within its design (Tijan et al., 2019). Blockchain technology is most apparent in cryptocurrencies and first gained its notoriety as a management platform for Bitcoin. Still, it has a broader scope of applicability in other industries, one being global logistics.

Global logistics is the system of maintaining the flow of goods through the supply chain, from a product's point of origin to its point of consumption; it links vital supply chain components. Blockchain technology's application in global logistics has implications of great significance and enormous potential, such as the capability to revolutionize the supply chain and rattle how goods are marketed, produced, purchased, and consumed. It can facilitate data exchange by capturing each process in the block and disbursing the data across several nodes (computers), thus, enabling transparency. Each block is connected to the preceding and succeeding one, resulting in a safer system. Additionally, Blockchain ensures reliability, data security, authenticity, and easy tracking by providing reliable data concerning shared products via a public block, increasing trust between supply chain actors and the end-user in the logistics process. So, as a whole, Blockchain technology has a potential to effectively increase the efficiency and transparency of the whole global logistic process from storage to delivery and payment. Although Blockchain has a broad scope of applicability, it is not without its challenges. One of the limitations is that it is a time-consuming process, as the verification of every transaction needs to be acknowledged at every node in the network (Tijan et al., 2019).

Yet Blockchain technology is an emerging technology there is no consensus regarding its application in logistics industry. In addition, the literature is insufficient to shed light on industrial applications in the field of logistics. Thus, to fulfill this gap, a literature review delineating the importance and applicability of Blockchain technology in global logistics and its opportunities and challenges commences the chosen framework of this paper. Following the literature review, the methods applied to this paper are deliberated. The next chapter leads to results and discussion, and the paper is concluded with closing remarks.

\section{Literature Review}

\subsection{Blockchain Technology}

Blockchain technology is a distributed digital ledger with the capacity to guarantee traceability, security, and transparency, showing the potential of easing global supply chain management problems (Vijai et al., 2021). Issaoui et al. (2019) stated that "Being an emerging technology, the Blockchain aims at storing and transmitting data in a secure, more transparent, and decentralized way." Bitcoin, a peer-topeer digital currency, is the most prevalent example of the application of blockchain technology. 
Essentially, Blockchain is considered a distributed database, which means all digital events that have occurred are recorded and shared between all participants in the Blockchain; once inputted, the data cannot be erased. It initiates the growth of an autonomous open, and scalable digital economy. Crosby et al. (2016) affirmed that excellent prospects exist in Blockchain technology, and the transformation has only just started. Table 1 delineates Blockchain's three key benefits compared to other mediums described by Tijan et al. (2019).

Table 1. Benefits of Blockchain technology

\begin{tabular}{cc}
\hline Benefit & Description \\
\hline Free access & It provides anonymity and is free to join \\
Integrity irreversibility of records & Inputted data cannot be altered or erased \\
Unabridged data & Data cannot be censored or omitted by any authority \\
\hline
\end{tabular}

Another critical advantage of blockchain technology is its immutability. All shared data concerning digital assets, past and present, can be authenticated at any point in the future, a distributed consensus (Crosby et al., 2016). Table 2 illustrates the basic properties of Blockchain.

Table 2. Basic properties of blockchain technology (Tijan et al., 2019)

\begin{tabular}{ccc}
\hline Transparent & Decentralized & Secure \\
\hline $\begin{array}{c}\text { Distributed ledger: A digital } \\
\text { version of a ledger to track and } \\
\text { follow data }\end{array}$ & $\begin{array}{c}\text { Peer-to-peer concept: Trading } \\
\text { takes place directly between the } \\
\text { sender and the recipient. }\end{array}$ & $\begin{array}{c}\text { Cryptography: In the moment a } \\
\text { transaction is approved by the } \\
\text { miners, it prevailes in a block, } \\
\text { which is embedded into the } \\
\text { Blockchain. }\end{array}$ \\
\hline
\end{tabular}

The decentralized nature of Blockchain is drawn from the fact that its operation is not dependent on a central authority. The decentralized transaction ledger functionality serves to confirm, register, and transfer any form of contract and property (Tijan et al., 2019). Issaoui et al. (2019) describe the steps in initiating a blockchain transaction as (1) Issue a new transaction, (2) Send the block that correlates to a new transaction to all nodes in the chain, (3) Approval of the recent transactions by the other nodes, (4) Addition of the new block to the chain, (5) Save a new duplicate of the book comprising of all the blocks on the network of nodes. Figure 1 illustrates the process involved in initiating a new blockchain transaction. Transactions initiated through blockchain technology are performed directly "peer-to-peer," result in cost reductions, expedited methods, and flexibility in various industries (Tijan et al., 2019).

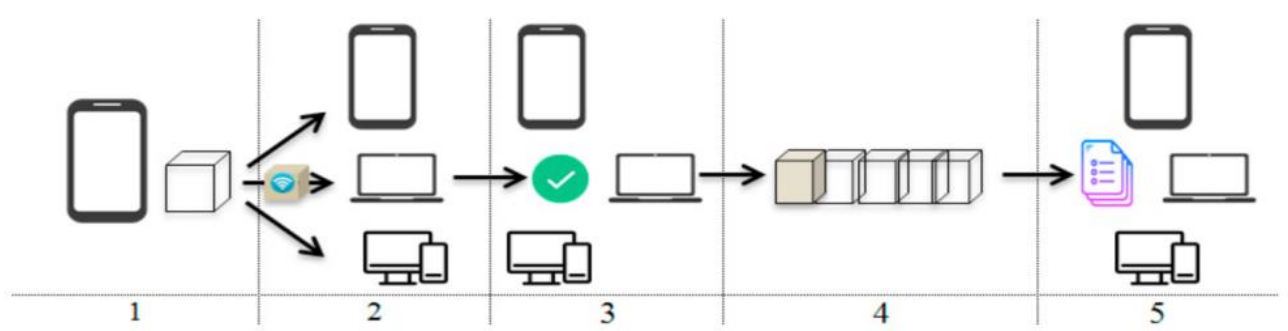

Figure 1. Steps to Create a New Blockchain Transaction (Issaoui et al., 2019) 


\subsection{Blockchain Technology's Applicability in Global Logistics}

The logistics industry, a trillion-dollar industry, is the mainstay of all businesses around the world. The supply chain is the network of all individuals, organizations, resources, activities, and technology involved in creating and selling a product. Blockchain can change the current supply chain management landscape with its capacity, traceability, authenticity, and reliability. Blockchain logistics utilizes a decentralized distributed ledger to ease the movement of information, goods, and finances (Vijai et al., 2021). The advent and growth of the fourth industrial revolution (industry 4.0) created opportunities to enhance supply chain processes. Industry 4.0 serves to improve speed, flexibility, productivity, sustainability, and quality. Tijan et al. (2019) affirmed that industry 4.0 is all-inclusive, with machines having a partial transfer of independence, understanding, and autonomous decision-making. Logistics 4.0 facilitates the assimilation and optimum streamlining of processes within corporate boundaries (Tijan et al., 2019). Issaoui et al. (2019) describe Smart logistics as utilizing new technologies such as the Internet of Things (IoT), Artificial Intelligence (AI), and Cloud computing. The assimilation of new technologies into management processes currently results in robust growth, particularly in Smart Logistics, which serves as a cornerstone of the fourth industrial revolution (Issaoui et al., 2019). The supply chain and logistics industry are fields where the application of blockchain technology is beneficial. The possible applications of Blockchain technology in logistics and transportation industry are summarized below regarding their efficiency and effectiveness in global logistics system:

Truck maintenance and authentication: Utilizing blockchain-based solutions in global logistics provides more supervisory control and management on all vehicles involved in the process. Companies can remain compliant by keeping track of maintenance records. Data on past performance of vehicles and maintenance records can be easily authenticated.

Expedited transactions and transaction processes: Concerning transactions, Blockchain maintains unanimity among all parties on the chain as they all have an identical version of the ledger. Collective confidence among all parties is increased, which in turn enhances efficiency and enables faster delivery of goods and services. Contracts and payment processes are protected, and transaction data is readily accessible by all parties involved.

Tracking effectiveness: Efficient real-time tracking is made possible through Blockchain; manufacturers, suppliers, and logistics partners can keep track of all necessary information from the point of origin of a product to the point of sale. This eases the mind by providing accurate information concerning logistics processes such as transportation, clearance, and delivery.

Enhanced safety and security: In a blockchain-based system, alterations to preceding blocks can only be implemented by reverting all transactions, which is costly. Thus, leaving the logistics process impervious.

Expedited processing times: Logistics processes and documentation are often time-consuming and may result in delays; with blockchain-based solutions, data exchange is seamless and instantaneous. Therefore, the time and resources wasted in mailing or scanning information and human error are significantly reduced. Maersk and IBM employed the use of blockchain technology as a means to reduce costs. Longman (2020) stated, "Maersk and IBM undertook a test case using avocados, shipped from 
Mombasa to Rotterdam. IBM calculated the cost of the moving the shipping container itself was roughly $\$ 2,000$, with paperwork making up around \$300 - between 15 percent and 20 percent of the total cost."

Minimized fraud: Due to the immutable nature of Blockchain technology, transactions are made more secure by eliminating areas where fraud occurs. Inputted information cannot be edited or erased, which reduces fraudulent operations. So, shippers can confirm authenticity by tracking when each document or transaction was modified. The first recorded application of Blockchain technology in the logistics field was by a start-up, Everledger, in April 2015, who used it to put up a fight against fraud in the diamond supply chain (Petersen et al., 2018).

\section{Methodology}

This qualitative study descriptively analysis and summarizes the past data (literature) regarding the applicability of the Blockchain technology in logistics. The approach of this study can be described as theory building from multiple case studies, which is becoming increasingly popular in social science (Eisenhardt \& Graebner, 2007). Compared to a single-case study, multiple-case studies are likely to provide a more substantial base for theory building (Rowley, 2002; Yin, 1994). A theoretical framework that pertains to the critical applications of Blockchain technology is what is presented in this paper. For identifying empirical studies used in our meta-analysis, we searched for the titles, abstracts or keywords which include terms of "Blockchain" and "logistics". A total of 14 articles were adequately suited to the study and gave insight either within the scope of the topic or by detailing the development of Blockchain technology. Table 3 surmises the papers utilized, with their topics of discussion.

Table 3. Papers focusing on Blockchain technology in global logistics

\begin{tabular}{ccc}
\hline Topic & Sources & Main discussed topics \\
\hline Blockchain generalities & (1) Badzar, 2016; (2) Pilkington, 2016 & $\begin{array}{c}\text { General description of } \\
\text { Blockchain technology, its } \\
\text { features, and benefits }\end{array}$ \\
$\begin{array}{c}\text { General applications of } \\
\text { Blockchain technology }\end{array}$ & $\begin{array}{c}\text { (3) Crosby et al., 2016; (4) Hargroves et al., } \\
\text { Applicability of blockchain } \\
\text { technology in various } \\
\text { industries }\end{array}$ \\
$\begin{array}{c}\text { Applicability of Blockchain } \\
\text { technology in logistics }\end{array}$ & $\begin{array}{c}\text { (7) Hackius \& Petersen, 2017; (8) Vijai et al., } \\
\text { Steiner, 2019; (11) Tijan et al., 2019; (12) Orji } \\
\text { et al., 2020 }\end{array}$ & $\begin{array}{c}\text { Applicability of Blockchain } \\
\text { technology in logistics }\end{array}$ \\
$\begin{array}{c}\text { Practical applications of } \\
\text { Blockchain technology in } \\
\text { the logistics industry }\end{array}$ & (13) Petersen et al., 2018; (14) Heng, 2021 & $\begin{array}{c}\text { Real-world practical } \\
\text { applications of blockchain } \\
\text { technology }\end{array}$ \\
\hline
\end{tabular}

Generally, the selection of cases in a multiple case study research and random sampling share the same objectives, in the sense that the cases should represent a varied population, thereby providing mixed data on the scope of theoretical interest. A key difference is that in a multiple case study design, the choice of cases needs to be made more substantively rather than the statistical basis to adequately represent a target population (Greene \& David, 1984).

This qualitative research aims to describe the various ways Blockchain technology can be applied in global logistics while highlighting possible challenges. The study shows that Blockchain technology has a wide breadth of application in global logistics systems and stands to enhance operations. 


\section{Blockchain Applicability Overview}

Blockchain technology generally offers a significant reduction in the risk of a system failure and tackles susceptibility concerned with the supply chain (Goudz \& Steiner, 2019). The application of Blockchain technology can be primarily categorized and clustered into four groups: Information, Transport, Management and Finance (Issaoui et al., 2019). Concerning information, Blockchain's application allows the monitoring, tracking, and validating all data flows to be more secure. Its application offers integration and comprises the registration of each asset as it goes through supply chain nodes, receipts, payments, order tracking, invoices, and other official documents (Tijan et al., 2019). Incorporating blockchain technology into shipping, paperwork delays, waste, and fraud will be lessened, problems will be recognized quicker, and sustainability will be enhanced (Issaoui et al., 2019). Blockchain can advance business transactions by enabling parties acquiring products and services to exceed payment constraints and reduce transfer charges, thereby easing logistics transaction processes and encouraging customers. Blockchain technology improves management processes by furnishing managers with a clear picture of the whole logistics process in real-time, enabling them to make prompt decisions founded on factual information (Issaoui et al., 2019).

\subsection{Potential Benefits of the Application of Blockchain Technology}

In comparison to clusters of Blockchain technology which are summarized above, Table 4 provides a more comprehensive view of the benefits of applying Blockchain technology in global logistics systems.

Table 4. Potential benefits of the application of Blockchain technology in global logistics systems (adapted from Badzar, 2016)

\begin{tabular}{ll}
\hline & - Reduced cost of transactions \\
Relative & - Customers have the benefit of being able to assess the product or supplier before \\
advantage & - Centralized governmental institutions are eliminated from the chain \\
& - Unrties have the decision of purchasing sustainable products and transports \\
- Furnishes customers with data regarding the origin of the product and freight course \\
- Transactions are easily performed by utilizing hashes rather than physical documents \\
- The risk of fraud or fake goods is lessened \\
- Tracing, tracking, and recycling of the product lifecycle is enhanced \\
- Allows monitoring, tracking, and tracing of transports \\
- Ease of use; register as a user and access the network \\
- Efficient usage of QR-codes, RFID, NFC-tags, WiFi or iBeacons \\
- Multiple platforms to access both private and public data \\
- A network-based platform with the function of exchanging tangible and intangible \\
Complexity & resources \\
\hline Trialability & - Active participation is not mandatory \\
& - The user can regulate the degree of participation and data exchanged \\
\hline Observability & Streamlines payment systems and the exchange of goods and services \\
\hline
\end{tabular}


According to other study, Hackius and Peterson (2017) argued four dimensions as benefits of adopting Blockchain technology to enhance processes in logistics which are summarized below:

Ease paperwork processing in ocean freight: Global shipping operations require significant amounts of physical documentation. Hackius and Peterson (2017) stated, "For example, shipping refrigerated goods from East Africa to Europe requires stamps and approvals from around 30 people and organizations that must interact with each other on over 200 occasions." With the application of Blockchain, costs, fraudulent activities associated with documentation, and human error will be reduced. The Port of Rotterdam employed a blockchain-based solution by launching "BlockLab" in order to swap out their paper-based "bill of lading" system with a digital system that facilitates real-time and tamperproof records to parties in the supply chain, thereby reducing transaction times and costs (Hargroves et al., 2021). Maersk, has already experimented with blockchain with Dutch Customs and US Department of Homeland Security

Enhanced freight tracking and authentication: The application of blockchain-based solutions in global logistics furnishes secure transaction records and reduces transaction times and costs. With safe and validated documents, verification, real-time tracking, product origin, and confirmation of delivery are supported, thereby allowing the release of funds (Hargroves et al., 2021). Including Walmart, Nestle and Unilever a number of firms have partnered an IBM-based Blockchain that allows tracking of food items.

Identify counterfeit products: The origin of high-priced and exclusive products is generally rendered on physical documentation, which could easily be altered, damaged, or misplaced. For example, counterfeit medicine is a prevalent issue in the pharmaceutical industry, and Blockchain can enhance patient safety by providing transparency from manufacturers all through to the patients.

Facilitate origin tracking: Most especially in the food supply chain industry, foodborne outbreaks are an issue for retailers. This issue can be curtailed by utilizing Blockchain technology, which enables tracking the origin of food items through farm origins, batch numbers, information on factory and processing, expiration dates, and shipping details. With the support of the Commonwealth Bank of Australia, a successful experiment was conducted in 2018 to track an international shipment of almonds by employing Blockchain (Hargroves et al., 2021). The increase in transparency that blockchain technology furnishes enables authorized users to have knowledge of the ownership structure of a product and its origin at any point in time (Goudz \& Steiner, 2019).

\subsection{Risks and Challenges of Blockchain Application}

Although Blockchain technology has extensive applications in global logistics, it is not exempt from risks and challenges. According to Tijan et al. (2019) "Blockchain technology suffers from scalability and performance issues." They go on to reiterate that it requires high power consumption and CPU power.

Real-time problem solving: The entire production could be easily affected by unforeseen circumstances such as unplanned demand and supply or natural disasters.

Absence of IT infrastructure: Several logistics providers have not yet taken advantage of the digital transformation ushered in by industry 4.0. By extension, they have not established IT infrastructure 
capable of withstanding blockchain technology. To achieve this feat, research and development, reorganization, and substantial investments are required.

The novelty of the technology: As blockchain technology is a relatively new technology, there are still a few issues concerning verification processes, transaction speeds, and data limits.

\subsection{Current Problems in Global Logistics and Blockchain-based Solutions}

Misinterpretation of data: The exchange of information and data in global logistics among various parties within the chain is linear and prone to errors. Once a break in the data exchange chain occurs due to corrupted, lost, or deleted data, the parties involved' retrieval becomes difficult; this gives way to threats. A high frequency of transactions characterizes global logistics. When data or information concerning those transactions is not easily retrieved in real-time, threats such as an increased frequency of return and exchange of goods and fraudulent activities compound the logistics process. Blockchain is a distributed ledger that is characterized by "decentralization" and ensures transparency. All parties involved in each node in the chain cooperatively control and manage the data. With the data distribution model being "centralized," the data is guaranteed reliable and data islands are eradicated (Heng, 2021).

High operation costs: Global logistics encompasses expensive activities within its processes. These activities come in the form of commodity inspections, tax declarations, customs clearances, packaging and distribution, warehousing, etc., and the aggregate cost is substantial. Blockchain technology offers effective and efficient automation. Blockchain-based smart contracts allow contracts to be automatically filled according to predetermined instructions without the intervention of the parties involved in the transaction and also the automatic execution of said instructions once the predetermined conditions have been met; this curtails delayed payments (Heng, 2021).

Lack of accountability concerning logistics incidents and accidents: The chain of information exchange in global logistics is often remote. This poses a difficulty in tracking and acknowledging the responsible party in incidents and accidents. Actors of the various processes control information and data. These processes are not interconnected; the consignor of the other process relates information or data required by another actor. Passing information from one party to another is time-consuming and involves cumbersome steps; thus, tracking the source of any incidents and accidents becomes significantly tricky.

Blockchain furnishes a traceability and time stamp function, which allows the whole process of product production and distribution to be tracked and documented. With this function, any issues that may arise during the logistics process can be easily traced back to the source, and the party involved can be held accountable. The limits of Blockchain technology are not a deterrent to its applicability in global logistics. Blockchain is being practically applied by several companies involved in global logistics worldwide; Table 5 describes the areas of application and real-world applications of blockchain technology in global logistics. 
Table 5. Applicable areas and practical applications of Blockchain technology in global logistics (Heng, 2021)

\begin{tabular}{|c|c|}
\hline Area of Application & Practical Applications \\
\hline $\begin{array}{l}\text { International supply chain logistics: } \\
\text { Curtailing the spread of counterfeit } \\
\text { goods }\end{array}$ & $\begin{array}{l}\text { - IBM and Walmart cooperated to develop blockchain-based } \\
\text { solutions regarding food safety. Walmart can now track produce in } \\
\text { the supply chain from Chinese markets and fresh vegetables from } \\
\text { its suppliers. }\end{array}$ \\
\hline $\begin{array}{l}\text { Importation of pharmaceutical goods } \\
\text { Importation of food }\end{array}$ & $\begin{array}{l}\text { Everledger used blockchain technology to track the origin of } \\
\text { diamonds (to avoid the sale of blood diamonds), gems, jewelry, } \\
\text { fine art, and wine, and also prevent the sale of counterfeit products }\end{array}$ \\
\hline International trade logistics: & - IBM and Maersk launched TradeLens, a blockchain-based freight \\
\hline Fulfillment of trade orders & platform, to enhance the efficiency of digital management, reduce \\
\hline Trade documentation & paper waste, unoccupied or mismatched containers, and fraud. \\
\hline Customs clearance & $\begin{array}{l}\text { - Tianjin Port Blockchain Verification Pilot Project was launched for } \\
\text { trial operation in China in } 2019 \text { and achieved the incorporation of } \\
\text { blockchain technology into international trade }\end{array}$ \\
\hline
\end{tabular}

\section{Discussion}

The study unveiled worthwhile observations concerning the adoption and applications of Blockchain technology in global logistics systems. Blockchain is still an emerging technology with a lack of standardization, which means there is no agreement on a common model; therefore, hesitance exists as to whether to adopt it. The absence of legislation and standards of use creates insecurity between stakeholders (Issaoui et al., 2019). Although Blockchain technology makes transaction processes more effortless, it still suffers from low transaction speeds, extending transaction times. Adopting blockchain technology and incorporating it into the existing system does not come easy; the process involves a change of management where employees have to be addressed and trained on its benefits applications. Blockchain technology is relatively new and still an evolving technology that is developing rapidly, so the challenges of implementation that currently exist may be more compound in the future.

However, despite the challenges concerning the adoption and implementation of blockchain technology, it still has far-reaching applications in global logistics systems. Blockchain technology enables truck and vessel tracking, maintenance, and authentication at a rudimentary level by offering the capability to have easily accessible data on the current and past truck and vessel records. With smart contracts, transactions and transaction processes are expedited because tasks that would have been carried out manually are done automatically. One of the most valuable applications of Blockchain technology concerns its capacity to effectively and efficiently track, record, and authenticate the entire logistics process of a product from its origin to its endpoint. Wine Chain, founded on the QTUM platform, a blockchain-based solution, facilitates the tracking and identification of the entire wine production and distribution process and provides easily accessible information of each bottle to consumers that they can view from their mobile phones (Heng, 2021). Blockchain technology ensures the safety and security of transactions and documentation due to inputted data being immutable, reducing fraudulent activities. The paper trail and physical documentation involved in logistics processes are immense and prone to human error, misplacement, or fraud. Still, by incorporating blockchain technology, the existing paper-laden system can be replaced with a digital system. The new blockchain-based digital system will allow all 
records to be easily accessible at any point in time, reduce costs and time, and mitigate the possibility of forgery.

The incorporation of Artificial Intelligence (AI) into Blockchain technology in the global logistics system is a concept worth considering. Blockchain technology's applicability can be additionally improved by combining AI features like deep learning algorithms and machine learning (Hargroves et al., 2021). In freight management, stored data is immutable and can easily be accessed in real-time to improve logistics processes. By incorporating AI, the stored data can be used to stage and store freight and optimize freight routes through machine learning. This instance gives insight into the endless possibilities and benefits the global logistics industry stands to gain from adopting and applying Blockchain technology.

\section{Conclusion}

The objective of this study was to highlight the potential applications of Blockchain technology in the field of global logistics. Through the utilization of extant literature, significant benefits of Blockchain's applicability in logistics were discovered. As a sum up, Blockchain technology stands to (1) enhance supply chain transparency and traceability, (2) ensure security, immutability and authenticity, (3) reduce process complexity and (4) improve operational efficiencies. These are benefits and applications of Blockchain technology that have the capacity to transform the current landscape of the global logistics industry. An additional benefit of Blockchain is its capacity to be incorporated with artificial intelligence, which broadens its scope of operation. Blockchain technology does have its limitations, but the benefits outweigh the burdens. Despite its limitation, the practical applications of Blockchain technology in global logistics show that its adoption is indeed beneficial. Blockchain technology offers concrete solutions to current issues in the global logistics industry, and the future of logistics is promising with its application. However, still, there is no single answer to the question of the potential value of Blockchain for logistic functions. Companies must develop their Blockchain-related capabilities, but also recognize the value this technology can create in certain use cases and installations.

\section{References}

Badzar, A. (2016). Blockchain for securing sustainable transport contracts and supply chain transparencyan explorative study of blockchain technology in logistics. Master thesis, Lung University.

Crosby, M., Pattanayak, P., Verma, S., \& Kalyanaraman, V. (2016). Blockchain technology: Beyond bitcoin. Applied Innovation, 2(6-10), 71.

Dobrovnik, M., Herold, D. M., Fürst, E., \& Kummer, S. (2018). Blockchain for and in Logistics: What to Adopt and Where to Start. Logistics, 2(3), 18. https://doi.org/10.3390/logistics2030018

Eisenhardt, K. M., \& Graebner, M. E. (2007). Theory building from cases: Opportunities and challenges. Academy of Management Journal, 50(1), 25-32. https://doi.org/10.5465/amj.2007.24160888

Goudz, A., \& Steiner, V. (2019). An evaluation for the use of blockchain technology in logistics. Complexity, 1(4). https://doi.org/10.11648/j.ijtet.20190501.12

Greene, D., \& David, J. L. (1984). A research design for generalizing from multiple case studies. Evaluation and Program Planning, 7, 73-84. https://doi.org/10.1016/0149-7189(84)90027-2

Hackius, N., \& Petersen, M. (2017). Blockchain in logistics and supply chain: trick or treat? In Digitalization in Supply Chain Management and Logistics: Smart and Digital Solutions for an 
Industry 4.0 Environment. Proceedings of the Hamburg International Conference of Logistics (HICL), (Vol. 23, pp. 3-18). Berlin: epubli GmbH.

Hargroves, K. C., Conley, D., \& Stantic, B. (2021). The Potential for Blockchain and Artificial Intelligence to Enhance the Transport Sector. Journal of Civil Engineering and Architecture, 15, 146-155. https://doi.org/10.17265/1934-7359/2021.03.003

Heng, R. (2021). Application of Blockchain Technology in the Field of International Logistics. Journal of Frontiers of Society, Science and Technology, 1(5), 83-90.

Issaoui, Y., Khiat, A., Bahnasse, A., \& Ouajji, H. (2019). Smart logistics: Study of the application of blockchain technology. Procedia Computer Science, 160, 266-271. https://doi.org/10.1016/j.procs.2019.09.467

Longman, N. (2020). Maersk and IBM are bringing blockchain tech to the shipping industry. SupplyChain. Retrieved May 12, 2021, from https://supplychaindigital.com/technology-4/maerskand-ibm-are-bringing-blockchain-tech-shipping-industry

Orji, I. J., Kusi-Sarpong, S., Huang, S., \& Vazquez-Brust, D. (2020). Evaluating the factors that influence blockchain adoption in the freight logistics industry. Transportation Research Part E: Logistics and Transportation Review, 141, 102025. https://doi.org/10.1016/j.tre.2020.102025

Petersen, M., Hackius, N., \& von See, B. (2018). Mapping the sea of opportunities: Blockchain in supply chain and logistics. it-Information Technology, 60(5-6), 263-271. https://doi.org/10.1515/itit-20170031

Pilkington, M. (2016). Blockchain technology: principles and applications. In Research Handbook on Digital Transformations. Edward Elgar Publishing. https://doi.org/10.4337/9781784717766.00019

Rowley, J. (2002). Using case studies in research. Management Research News, 25(1), 16-27. https://doi.org/10.1108/01409170210782990

Saberi, S., Kouhizadeh, M., Sarkis, J., \& Shen, L. (2019). Blockchain technology and its relationships to sustainable supply chain management. International Journal of Production Research, 57(7), 21172135. https://doi.org/10.1080/00207543.2018.1533261

Tijan, E., Aksentijević, S., Ivanić, K., \& Jardas, M. (2019). Blockchain technology implementation in logistics. Sustainability, 11(4), 1185. https://doi.org/10.3390/su11041185

Vijai, C., Suriyalakshmi, S. M., \& Elayaraja, M. (2021). Blockchain technology in logistics: Opportunities and challenges. Pacific Business Review International, 13(7), 147-151.

Yin, R. (1994). Case study research: Design and Methods (2nd ed.). Sage. 